\begin{tabular}{c|c|c|}
\hline \hline & MARINE ECOLOGY PROGRESS SERIES \\
Vol. 278: 291-296, 2004 & Mar Ecol Prog Ser & Published September 7 \\
\hline \hline
\end{tabular}

\title{
Feeding history influences otolith shape in tropical fish
}

\author{
Monica Gagliano*, Mark I. McCormick
}

School of Marine Biology and Aquaculture, James Cook University, Townsville, Queensland 4811, Australia

\begin{abstract}
The influence of feeding history on otolith shape and symmetry was examined in juveniles of 2 species of coral reef fish, Amphiprion akindynos and Pomacentrus amboinensis. Fast Fourier analysis was used to describe the shape of otoliths of fish from a variety of experimental feeding treatments, ranging from starvation, through pulse feeding, to feeding ad libitum. The resulting harmonics from both the left and right otoliths of each individual fish were used in a multivariate analysis to investigate shape differences among feeding treatments in the 2 species. When left and right otoliths were analysed separately, no significant differences between feeding treatments were revealed for either species. In contrast, when left and right otoliths from individuals were analysed together, clear separations in feeding groups were observed in both species. Differences among feeding treatments were largely due to differences in the finer details of the otolith shape, represented by the middle level harmonics. Fish that had been starved had significantly different otolith shapes than fish from all other treatments. Differences in otolith shape could not simply be attributed to differences in fish size or age among treatments. We conclude that differences in otolith shape are influenced by recent feeding history, but processes that influence otolith shape are complex and most likely species-specific. This study presents new evidence that otolith shape of tropical fish may directly reflect body condition of individuals regardless of fish size and age.
\end{abstract}

KEY WORDS: Otolith · Asymmetry · Condition · Feeding · Shape analysis · Fourier descriptors · Growth $\cdot$ Coral reef fish

Resale or republication not permitted without written consent of the publisher

\section{INTRODUCTION}

Otoliths have long been used to determine age and growth in fish, and are a popular tool for the discrimination of species (e.g. Hecht \& Appelbaum 1982, L'Abée-Lund 1988) and populations (e.g. Messieh 1972, McKern et al. 1974, Neilson et al. 1985). A number of studies have shown that otolith outlines can be used to define stock differences related to geographic locations (e.g. Bird et al. 1986, Castonguay et al. 1991, Smith 1992, Campana \& Casselman 1993, Friedland \& Reddin 1994, Begg \& Brown 2000) and to chemical and physical qualities of the environment (e.g. Campana \& Neilson 1985, Mosegaard et al. 1988, Lombarte \& Lleonart 1993).

The utility of otolith shape analysis extends beyond these differentiations, as it provides insights into events that influence otolith growth (Bird et al. 1986,
Smith 1992, Campana \& Casselman 1993, Begg \& Brown 2000). Implicit in these considerations is the assumption that otolith growth is highly correlated to fish somatic growth, which in turn is influenced by environmental or abiotic conditions (e.g. water temperature). While it might be expected that gross otolith shape is genetically controlled and that otolith morphology changes as the fish ages, the potential contribution of biotic factors (e.g. food availability) to the subtleties of otolith shape has received little attention, despite evidence suggesting that feeding history is reflected in other otolith growth characteristics (Molony \& Sheaves 1998, Searcy \& Sponaugle 2000). While a positive, though possibly lagged, relationship between otolith size and food availability is predicted (e.g. Molony \& Sheaves 1998), a direct link between the shape of the otolith and fish feeding history remains to be established. 
The broad aim of this study was to examine the sensitivity of otolith shape to different food regimes in juveniles of 2 species of tropical damselfish (Pomacentridae) and compare this measure to other standard proxies for body growth and condition. Further, we investigated the ability of otholiths to discriminate between feed regimes when the otoliths of the right and left sagittae are examined separately, compared to when they are considered together.

\section{MATERIALS AND METHODS}

Two species of coral reef fish (from the family Pomacentridae) were the focus of the present experiment: the Barrier Reef anemone fish Amphiprion akindynos and the Ambon damsel Pomacentrus amboinensis. Juvenile $A$. akindynos originated from a single clutch of full-sibling eggs and were reared for $30 \mathrm{~d}$ at the James Cook University aquarium facilities. Juvenile $P$. amboinensis were collected off Lizard Island, northern Great Barrier Reef, Australia (14 $\left.{ }^{\circ} 40^{\prime} \mathrm{S}, 145^{\circ} 28^{\prime} \mathrm{E}\right)$. Right and left sagittae were examined for a total of 68 juveniles to determine the effect of periodic feeding on otolith shape. Each fish was maintained individually in a 31 aquarium with a flow-through seawater system $\left(24 \mathrm{l} \mathrm{h}^{-1}\right)$. Water within each aquarium system was held at a temperature of $29 \pm 0.5^{\circ} \mathrm{C}$ and a salinity of $34 \pm$ $0.1 \mathrm{ppt}$. The aquaria were kept under a $12 \mathrm{~h}$ light:12 h dark cycle. Juveniles were all equally fed 24 to $36 \mathrm{~h}$ old Artemia sp. nauplii throughout a $3 \mathrm{~d}$ acclimation period and then randomly assigned to different feeding regimes for a $13 \mathrm{~d}$ experimental period. The feeding regimes used were thought to cover a realistic spectrum of food availability in the wild. Eighteen $P$. amboinensis juveniles were randomly assigned (6 per treatment) to one of 3 feeding regimes: (1) fed ad libitum, (2) fed once day and (3) fed every second day. Fifty $A$. akindynos individuals were randomly assigned (10 per treatment) to 1 of 5 feeding regimes: (1) fed ad libitum, (2) fed once day, (3) fed every second day, (4) starved for $4 \mathrm{~d}$ and then fed ad libitum for $9 \mathrm{~d}$ and (5) starved for $4 \mathrm{~d}$. Fish starved and sacrificed at Day 4 (A. akindynos treatment 5) were used as a control treatment in the otolith shape analysis. As such fish are expected to have markedly different otolith shapes than fish from all other feeding treatments, these individuals were used to test the sensitivity of this new approach using otolith shape to identify feeding history.

Fish size (standard length, SL) and body condition (hepato-somatic index HSI, calculated as proportion of liver weight to body weight) were measured on all specimens at the end of the $13 \mathrm{~d}$ experiment, prior to otolith removal. The sagittal pair of otoliths was then located and removed from the braincase under a dis- secting microscope. Each otolith was cleaned in distilled water and stored dry, with a record of its identity and whether it was from the left or right side of the fish.

To determine whether recent feeding history influenced sagittal shape, the 2-dimensional shape of the otoliths of all fish was quantified using Fast Fourier analysis. A grey-scale image of each otolith was captured using a video image-analysis system linked to a compound microscope at $10 \times$ magnification. The image analysis software package, OPTIMAS (version 6.5), was then used to measure otolith size (maximum otolith length, MOL) and to calculate Fast Fourier shape descriptors ( $F F d$, also termed 'harmonics') from the silhouette of each otolith. The distal edge of the otolith rostrum was chosen as a common landmark point to start each of the automated tracings. The 2dimensional shape was represented by a series of successive cosine waves, having amplitude and phase angle components. The amplitude of each cosine wave was the shape descriptor or harmonic, calculated according to the relationship described by Christopher \& Waters (1974). This yielded 128 radial lengths from the shape centroid (used as otolith centre) measured at equal intervals in a $360^{\circ}$ radius (Media Cybernetics 1999). The number of harmonics to be used as shape descriptors for the left and right sagittae of each fish was set to the first 20, excluding the 0th harmonic. The 0th harmonic represents the mean radius of the shape (Bird et al. 1986) and all harmonics were divided by this in order to standardise for otolith size (Castonguay et al. 1991). The first 6 harmonics are referred to as low-order harmonics and determine the gross shape of the otolith, such as its elongation, triangularity and squareness. Successively higher order harmonics measure increasingly finer details in the otolith silhouette.

Analysis of variance (1-way ANOVA) was performed to determine whether fish size, body condition and otolith size differed among treatments. Tukey's HSD means comparisons were used to determine the nature of significant differences found in ANOVA. The assumption of normality and homogeneity of variance were examined and data transformed using natural log when assumptions were not met. Multivariate analysis of variance (MANOVA) was used to test the hypothesis of no difference in otolith shape for both species among feeding treatments. The nature of significant differences among treatments found by MANOVA was explored and displayed using canonical discriminant analysis (CDA). This technique allowed us to identify a number of trends in the dataset (canonical variates) that maximally discriminated among the experimental groups (feeding treatments). The feeding groups were represented as treatment centroids with $95 \%$ confidence clouds (Seber 1984). Trends in the original variables (i.e. Fourier descriptors) were displayed graphi- 
Table 1. Pomacentrus amboinensis and Amphiprion akindynos. Comparison of 6 measures of body condition for juvenile fish subjected to 3 (P. amboinensis; a) or 5 (A. akindynos; b) feeding treatments. Results of 1-way ANOVAs and multivariate analysis of variance (MANOVA) are given. Variables included hepatosomatic index (HSI), body size (standard length SL, mm), otolith size (maximum otolith length MOL, mm) and otolith shape (Fast Fourier descriptors, FFd). Data were ln-transformed to improve homogeneity of variance. Wilks' lambda $(\lambda)$ was used as the multivariate test statistic. ${ }^{*}$ significant at $p<0.05$ and ${ }^{* *}$ significant at $\mathrm{p}<0.001$

\begin{tabular}{|c|c|c|c|c|c|c|c|c|c|c|}
\hline \multirow[t]{2}{*}{ Variable } & \multirow[t]{2}{*}{ Source } & \multirow[t]{2}{*}{ MS } & \multicolumn{3}{|c|}{ ANOVA } & \multirow[t]{2}{*}{ Variable } & \multirow[t]{2}{*}{ Source } & \multicolumn{3}{|c|}{ MANOVA } \\
\hline & & & $\mathrm{df}$ & $F$ & $\mathrm{p}$ & & & $F$ & df & $\mathrm{p}$ \\
\hline \multicolumn{11}{|c|}{ (a) P. amboinensis } \\
\hline HSI & $\begin{array}{l}\text { Treatment } \\
\text { Error }\end{array}$ & $\begin{array}{l}6.566 \\
0.117\end{array}$ & $\begin{array}{r}2 \\
15\end{array}$ & 56.059 & $<0.001^{* *}$ & MOL pair & Treatment & 0.976 & 4,26 & 0.432 \\
\hline \multirow[t]{2}{*}{ SL } & Treatment & 0.085 & 2 & 6.808 & $<0.05^{*}$ & FFd right & Treatment & 0.871 & 28,2 & 0.668 \\
\hline & Error & 0.013 & 15 & & & left & Treatment & 4.472 & 28,2 & 0.199 \\
\hline \multirow[t]{2}{*}{ MOL right } & Treatment & 0.036 & 2 & 1.542 & 0.248 & pair & Treatment & 57.981 & 28,2 & $<0.05^{*}$ \\
\hline & Error & 0.023 & 14 & & & & & & & \\
\hline \multirow[t]{2}{*}{ left } & Treatment & 0.034 & 2 & 1.386 & 0.282 & & & & & \\
\hline & Error & 0.025 & 14 & & & & & & & \\
\hline \multicolumn{11}{|c|}{ (b) A. akindynos } \\
\hline \multirow[t]{2}{*}{ HSI } & Treatment & 0.301 & 3 & 3.676 & $<0.05^{*}$ & MOL pair & Treatment & 2.502 & 6,46 & $<0.05^{*}$ \\
\hline & Error & 0.082 & 36 & & & & & & & \\
\hline \multirow[t]{2}{*}{ SL } & Treatment & 2.201 & 3 & 0.883 & 0.459 & FFd right & Treatment & 1.041 & 80,30 & 0.469 \\
\hline & Error & 2.492 & 36 & & & left & Treatment & 1.056 & 80,30 & 0.447 \\
\hline \multirow[t]{2}{*}{ MOL right } & Treatment & 0.012 & 3 & 5.472 & $<0.05^{*}$ & pair & Treatment & 28.422 & 104,6 & $<0.001^{* *}$ \\
\hline & Error & 0.002 & 27 & & & & & & & \\
\hline \multirow[t]{2}{*}{ left } & Treatment & 0.007 & 3 & 2.581 & 0.074 & & & & & \\
\hline & Error & 0.003 & 27 & & & & & & & \\
\hline
\end{tabular}

cally as vectors, with the relative importance of these variables in discriminating among groups represented by the length of the vectors.

\section{RESULTS}

Body size (SL) of Pomacentrus amboinensis fed ad libitum was significantly different only from those fed every second day $\left(F_{2,15}=6.81, \mathrm{p}<0.05\right.$, followed by Tukey's HSD tests) at termination of feeding trials. The size of individuals from both groups did not differ from fish fed once per day. No significant differences were observed in otolith size (MOL) among the 3 groups, whether right and left were considered separately or included in the same MANOVA analysis as independent units (Table 1).

All 3 feeding groups could be clearly distinguished from one another on the basis of body condition (HSI), measured as the proportion of liver weight to body weight $\left(F_{2,15}=56.06, \mathrm{p}<0.001\right.$, followed by Tukey's HSD tests). Fish fed ad libitum had higher body condition than fish from the fed once per day treatment, while fish fed every second day displayed the lowest body condition.

When left and right otoliths were analysed separately, the different feeding treatments could not be discriminated using otolith shape (Table 1). However, when shape descriptors from the left and right sagittae were included in the same analysis as independent units, clear differences were found among all treatments (Wilks' $\lambda, p<0.05$ ). These trends were illustrated by CDA, which showed that the 3 feeding groups for Pomacentrus amboinensis could be successfully distinguished on the basis of otolith shape (Fig. 1). Over $95 \%$ of the total variation among $P$. amboinensis experimental feeding groups was accounted for by Canonical Variate 1. Separation of the 3 centroids was largely due to differences in the magnitude of the middle and higher level harmonics (Fig. 1), suggesting that most of the discrimination related to the finer details of the shape of the otolith pairs.

In contrast to the results for Pomacentrus amboinensis, the body size (SL) of Amphiprion akindynos was not significantly influenced by the feeding treatments (Table 1). However, fish from the 4 treatments differed significantly in body condition, (HSI $F_{3,36}=3.68, \mathrm{p}<$ 0.05). Fish fed once per day had significantly higher HSI than those fed every second day. Fish fed ad libitum, and fish initially starved for $4 \mathrm{~d}$ and then fed ad libitum, displayed the highest levels of HSI, though these 2 treatments did not differ from each other and HSI did not differ significantly between these fish and fish under the other 2 feeding regimes (fish fed once per day and fish fed every second day). 


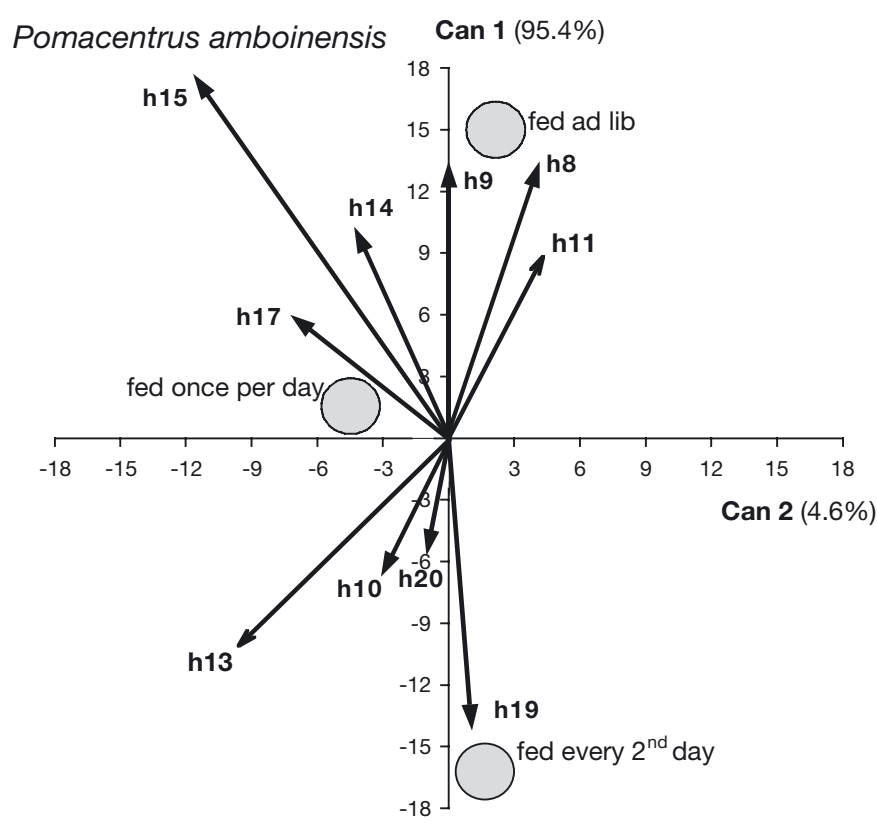

Fig. 1. Pomacentrus amboinensis. Comparison of the shape of sagittal otoliths from juveniles exposed to 3 different feeding treatments. A canonical discriminant analysis is displayed with treatment centroids and $95 \%$ confidence clouds plotted together with the direction and importance (as indicated by the length of the vector) of trends in measured otolith shape descriptors (the first 10 most significant harmonics are plotted). Can: canonical variate

The feeding groups could not be distinguished from each other (based on right otolith measurements) or could only be partially distinguished (based on left otolith size and left and right otolith size together; Table 1) by otolith size. Otoliths of fish fed ad libitum were significantly longer than otoliths from fish fed every second day. However, no other differences in otolith size amongst fish allocated to the 4 feeding regimes were found.

Shape analysis of Amphiprion akindynos otoliths discriminated feeding histories similarly to that of Pomacentrus amboinensis (Table 1b). Otoliths from fish that had been starved (Treatment 5) were also included in this analysis. When shape descriptors from the left and right otoliths were incorporated in the same analysis as independent units, clear differences were found among all 5 treatments (Wilks' $\lambda, p<0.001$ ). In accordance with our hypothesis, fish that were starved had markedly different otolith shapes than fish from all other feeding treatments (Fig. 2). The discrimination among feeding treatments was attributable to a mixture of harmonics of varying magnitude. Differences among treatments could not be simply interpreted as any one aspect of otolith shape, but rather by a combination of coarse and fine-scale shape differences.

\section{DISCUSSION}

For 3 decades researchers have acknowledged that otoliths are historic records of the growth history of individuals (Panella 1971, Campana \& Neilson 1985, Campana \& Jones 1992, Thorrold \& Hare 2002). Otolith growth is sensitive to changes in feeding and temperature history, but responds conservatively to changes in conditions and often with a lagged response (e.g. Molony \& Choat 1990, Milicich \& Choat 1992, Molony \& Sheaves 1998). Although these studies suggest that otolith size should change with the growth environment, this is the first study to examine the response of otolith shape to changing growing conditions.

Our data suggests that otolith shape embodies a sensitive record of individual recent feeding histories of 2 tropical reef fishes. While other studies have emphasised the utility of otolith shape analysis in differentiating populations, stocks and species (e.g. Smith 1992, Begg \& Brown 2000, Stransky 2001), the present study using recent feeding history suggests that otolith shape can be used to discriminate much finer scale events. We demonstrated that biotic factors,

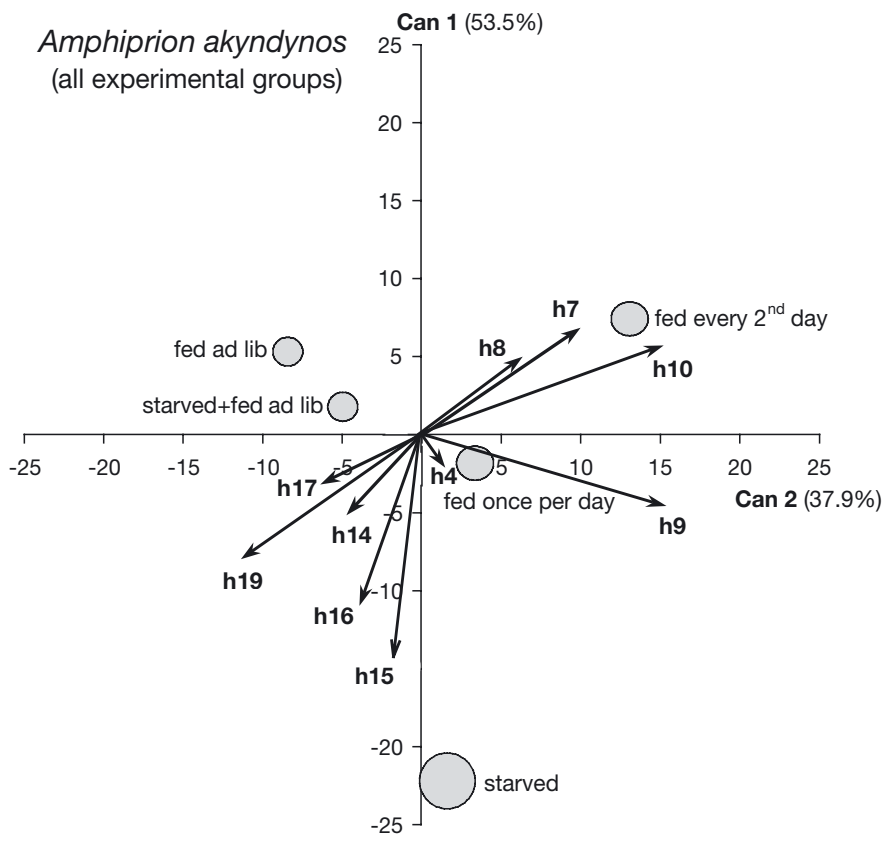

Fig. 2. Amphiprion akindynos. Comparison of the shape of sagittal otoliths from juveniles exposed to 5 different feeding treatments, 4 of which included different levels of food availability, and 1 of which represents a starved group. A canonical discriminant analysis is displayed with treatment centroids and $95 \%$ confidence clouds plotted together with the direction and importance (as indicated by the length of the vector) of trends in measured otolith shape descriptors (the first 10 most significant harmonics are plotted). Can: canonical variate 
such as food availability, also influence shape, and may leave a record of previous feeding conditions in the otolith once appropriately ground-truthed.

Measures of body condition differ markedly in their sensitivities (see Ferron \& Legget 1994), both with respect to the magnitude of environmental change that they respond to and their temporal concordance with that change (Suthers 2000). In the present study, body length was less sensitive to varying feeding conditions than relative liver weight (HSI), the former integrating more bodily processes than the latter. The combined shape of the right and left otolith was the most sensitive indicator examined in the present study. Typically body condition is measured using soft body parts such as intestine and liver, which are directly involved in metabolic processes and whose lipid storage are reliable indicators of the nutritional status of the fish (e.g. Margulies 1993, Theilacker et al. 1996, Green \& McCormick 1999). As lipids can be processed within hours and larval and juvenile fish can turn them over rapidly, they do not provide a permanent record of the feeding history of the fish. The advantage otolith shape offers is that otoliths are a permanent record and no reabsorption occurs. A comparison of the feeding histories of the anemone fish experiment suggests that otolith shape responded to food availability on a scale of less than $4 \mathrm{~d}$. The consistent discrimination between all feeding groups in both study species using the otolith (pair) shape is strong support for its use to assess short-term feeding histories in juvenile fish.

The utility of otolith shape to discriminate among different feeding histories may aid our understanding of magnitude and periodicity of feeding in wild populations, particularly that of larval stages that have a shorter temporal buffer between an absence of food and starvation. The spatial and temporal patchiness of food during the larval period has long been suggested as an important mechanism underlying cohort success (Hjort 1914, Leggett \& DeBlois 1994). However, the tools available to date have only been able to reveal very recent feeding histories (e.g. RNA/DNA ratios, cell cycle analysis, gut epithelium cell height), or an integrated feeding history (e.g. Fulton's $K$, relative lipid content), rather than the short-term fluctuations in past feeding events. Evidence from the present study suggests that otolith shape responds in a similar way to other, more commonly measured means of quantifying body condition, but may be a more sensitive and lasting record. Clearly, more experimental studies are required to facilitate the interpretation of otolith shape in relation to longer-term feeding history. The exciting possibility of back-calculating otolith shape at a daily resolution and using it to infer fluctuations in calorific intake awaits further experimentation.
In both species, differences in otolith shape relative to feeding history were mainly found in the middle and higher level Fourier harmonics, suggesting that variations occurred in both the coarse shape characteristics as well as the more subtle outline crenations. These variations could be attributable to differences in the rate and mode of growth of the right and left otolith respectively (Bird et al. 1996). While the pathways involved in controlling the mode of growth of the 2 otoliths are not understood, it is possible that asymmetry exists. Deviations from perfect bilateral symmetry in a particular trait are caused by a variety of stressors, including low food quality and or quantity (Parson 1990). Short-term changes in fish condition (e.g. limited food supply and/or starvation) induced in this experiment affected the shape of otolith pairs. Although the mechanisms that produce or regulate the observed differences in this bilateral trait remain unexplored, our results encourage the use of the otolith pair as a unit. The information obtained from a shape analysis based on both otoliths together can yield a sensitive record of past growth events; this detailed information may be lost when only 1 otolith of the pair is examined.

Our evidence suggests that the otolith shape of juvenile fish may reflect the body condition of individuals independently of their size or age. Although shape will inevitably change with ontogeny, this did not explain the differences in shape amongst treatments. Since changes in otolith shape were subtle, our finding is not incompatible with the ubiquitous finding of a positive relationship between somatic and otolith growth (e.g. Messieh 1975, Meekan et al. 1998, Vigliola et al. 2000, Morita \& Matsuishi 2001), since there is often considerable variability in fish-size/otolith-size relationships, particularly at specific ages or at key developmental stages (e.g. Chambers \& Leggett 1987, McCormick 1994). Most importantly, the otolith shape of individuals examined in this study was not affected by the confounding effects of size or age. Otolith shape analysis may therefore provide new information on the condition of fish and their developmental trajectories by linking growth, development and body condition together in a manner that is not related to fish size or age.

Otolith shape analysis represents an approach that is complementary, rather than an alternative, to detailed studies of growth history from otoliths. We suggest that otolith shape analysis may provide insights on events affecting fish growth and condition at any particular time; however, further studies are required to enable us to decode the information held within otolith shape.

Acknowledgements. We thank K. Buchler for providing the Amphiprion akindynos juveniles used in this experiment. We thank S. Campana for his insightful comments on the study. 
H. Choat, M. Depczynski, C. Fulton and B. Green provided constructive comments on the manuscript. Special thanks to M. Gristina for his support and encouragement on this study. This research was funded through an Australian Research Council Discovery grant to MIM and a Pinerolo Rotary Club Award to MG. JCU Ethics Approval Number A836_03.

\section{LITERATURE CITED}

Begg GA, Brown RW (2000) Stock identification of haddock Melogrammus aeglefinus on Georges Bank based on otolith shape analysis. Trans Am Fish Soc 129:935-945

Bird JL, Eppler DT, Checkley DM (1986) Comparison of herring otoliths using Fourier series shape analysis. Can J Fish Aquat Sci 43:1228-1234.

Campana SE, Casselman JM (1993) Stock discrimination using otolith shape analysis. Can J Fish Aquat Sci 50: 1062-1083

Campana SE, Jones CM (1992) Analysis of otolith microstructure data. In: Stevenson DK, Campana SE (eds) Otolith microstructure examination and analysis. Can Spec Publ Fish Aquat Sci 117:73-100

Campana SE, Neilson JD (1985) Microstructure of fish otoliths. Can J Fish Aquat Sci 42:1014-1032

Castonguay M, Simard P, Gagnon P (1991) Usefulness of Fourier analysis of otolith shape for Atlantic mackerel (Somber scombrus) stock discrimination. Can J Fish Aquat Sci 48:296-302

Chambers RC, Leggett WC (1987) Size and age at metamorphosis in marine fishes: an analysis of laboratory-reared winter flounder (Pseudopleuronectes americanus) with a review of variation in other species. Can J Fish Aquat Sci 44:1936-1947

Christopher RA, Waters JA (1974) Fourier series as a quantitative descriptor of miospore shape. J Paleontol 48: 697-709

Ferron A, Leggett WC (1994) An appraisal of condition measures for marine fish larvae. Adv Mar Biol 30:217-303

Friedland KD, Reddin DG (1994) Use of otolith morphology in stock discriminations of Atlantic salmon (Salmo salar). Can J Fish Aquat Sci 51:91-98

Green BS, McCormick MI (1999) Influence of larval feeding history on the body condition of Amphiprion melanopus. J Fish Biol 55:1273-1289

Hecht T, Appelbaum S (1982) Morphology and taxonomic significance of the otoliths of some bathypelagic Anguilloidei and Saccopharyngoidei from the Sargasso sea. Helgol Meeresunters 35:301-308

Hjort J (1914) Fluctuation in the great fisheries of northern Europe reviewed in the light of biological research. Rapp P-V Reun (Dan) 20:1-228

L'Abée-Lund JHL (1988) Otolith shape discriminates between juvenile Atlantic salmon Salmo salar L., and brown trout, Salmo trutta L. J Fish Biol 33:899-903

Leggett WC, DeBlois E (1994) Recruitment in marine fishes: is it regulated by starvation and predation in the egg and larval stages? Neth J Sea Res 32:119-134

Lombarte A, Lleonart J (1993) Otoliths as natural tags in the systematics of salmonids. Environ Biol Fish 36:389-393

Margulies D (1993) Assessment of the nutritional condition of larval and early juvenile tuna and Spanish mackerel (Pisces, Scombridae) in the Panama Bight. Mar Biol 115: 317-330

McCormick MI (1994) Variability in age and size at settlement of the tropical goatfish Upeneus tragula (Mullidae) in the northern Great Barrier Reef. Mar Ecol Prog Ser 103:1-15
McKern JL, Horton HF, Koski KV (1974) Development of steelhead trout (Salmo gairdneri) otoliths and their use for age analysis and for separating summer from winter races and wild from hatchery stocks. J Fish Res Board Can 31:1420-1426

Media Cybernetics (1999) OPTIMAS 6.5 User guide and technical reference, 9th edn. Media Cybernetics, Silver Spring, MD

Meekan MG, Dodson JJ, Good SP, Ryan DAJ (1998) Otolith and fish size relationships, measurement error, and sizeselective mortality during the early life of Atlantic salmon (Salmo salar). Can J Fish Aquat Sci 55:1663-1673

Messieh SN (1972) Use of otoliths in identifying herring stocks in the Southern Gulf of St. Lawrence and adjacent waters. J Fish Res Board Can 29:1113-1118

Messieh SN (1975) Growth of the otoliths of young herring in the Bay of Fundy. Trans Am Fish Soc 4:770-772

Milicich MJ, Choat JH (1992) Do otoliths record changes in somatic growth rate-conflicting evidence from a laboratory and field study of a temperate reef fish, Parika scaber. Aust J Mar Freshw Res 43:1203-1214

Molony BW, Choat JH (1990) Otolith increment widths and somatic growth rate: the presence of a time-lag. J Fish Biol 37: 541-551

Molony BW, Sheaves MJ (1998) Otolith increment widths and lipid contents during starvation and recovery feeding in adult Ambassis vachelli (Richardson). J Exp Mar Biol Ecol 221:257-276

Morita K, Matsuishi T (2001) A new model of growth backcalculation incorporating age effect based on otoliths. Can J Fish Aquat Sci 58:1805-1811

Mosegaard H, Svedang H, Taberman K (1988) Uncoupling of somatic and otolith growth rates in Arctic char (Salvelinus alpinus) as an effect of differences in temperature response. Can J Fish Aquat Sci 45:1514-1524

Neilson JD, Geen GH, Chan B (1985) Variability in dimensions of salmonid otolith nuclei: implications for stock identification and microstructure interpretation. Fish Bull 83:81-89

Panella G (1971) Fish otoliths: daily growth layers and periodic patterns. Science 173:1124-1127

Parson PA (1990) Fluctuating asymmetry: an epigenetic measure of stress. Biol Rev 65:131-145

Searcy SP, Sponaugle S (2000) Variable larval growth in a coral reef fish. Mar Ecol Prog Ser 206:213-226

Seber GAF (1984) Multivariate observations. John Wiley \& Sons, New York

Smith MK (1992) Regional differences in otolith morphology of the deep slope red snapper Etelius carbunculus. Can J Fish Aquat Sci 49:795-804

Stransky C (2001) Preliminary results of a shape analysis of redfish otoliths: comparison of areas and species. NAFO SCR Doc 01/14, Ser No N4382

Suthers I (2000) Significance of larval condition: comments on laboratory experiments. Can J Fish Aquat Sci 57: 1534-1536

Theilacker GH, Bailey KM, Canino MF, Porter SM (1996) Variations in larval walleye Pollock feeding and condition: a synthesis. Fish Oceanogr 5(1):112-123

Thorrold SR, Hare JA (2002) Otolith applications in reef fish ecology. In: Sale PF (ed) Coral reef fishes-dynamics and diversity in a complex ecosystem. Academic Press, San Diego, p 243-264

Vigliola L, Harmelin-Vivien M, Meekan MG (2000) Comparison of techniques of back-calculation of growth and settlement marks from the otoliths of three species of Diplodus from the Mediterranean Sea. Can J Fish Aquat Sci 57: 1291-1299 